\title{
Globalização, gênero e construção da paz
}

\section{Globalización, género, y construcción de la paz}

\section{Globalization, gender and building of the peace}

\author{
Giovanni Felipe Catenaci \\ giovannicatenaci@hotmail.com
}

"Quais são os impactos da globalização na religião e nas comunidades religiosas?" (PUI-LAN, 2015, p. 10). É justamente a partir dessa questão que a teóloga chinesa Kwok Pui-Lan buscará refletir em seu texto Globalização, gênero e construção da paz (2015).

Situada no campo dos estudos de gênero pós-coloniais, a autora defende em seu livro que as religiões - a despeito dos séculos de abusos engendrados pelo colonialismo, não obstante a violência ignóbil dos fundamentalismos religiosos ainda vigentes em nossos dias - têm muito que contribuir para com o futuro da sociedade global. Sua principal contribuição neste livro refere-se ao diálogo interfé. De acordo com Pui-Lan, para além do diálogo inter-religioso, indica que "as conversações e interações estão acontecendo entre pessoas que pertencem a credos, e não entre religiões em si, entre religiões como sistemas de crenças e práticas" (PUI-LAN, 2015, p. 21) -, e isso permite que seja possível a construção de uma cultura da solidariedade e da paz. Em todo caso, por meio do diálogo interfé, sinalizando a necessidade de repensarmos, inclusive o conceito religião, a fim de que sejam superados os essencialismos ocidentais, Pui-Lan afirma que "é imperioso para as pessoas de todos os credos trabalhar rumo a um futuro no qual a religião possa ser uma força não para a destruição, mas para o bem comum" (PUI-LAN, 2015, p. 32). Nesse sentido, a fim de sustentar tal afirmação, Pui-Lan irá dividir seu texto em três capítulos. Os quais buscaremos esmiuçar a seguir. 
Primeiramente, a autora introduz o tema da pluralidade religiosa e toda a problemática que esta suscita, com a articulação de uma leitura histórica panorâmica acerca da trajetória do diálogo interfé. Seu objetivo é demonstrar que historicamente é possível constatarmos que as religiões estão se abrindo a uma postura dialogal; obviamente que se tratam de forças ambivalentes, haja vista que se, por um lado, encontramos os esforços ecumênicos do Conselho Mundial de Igrejas, por exemplo, por outro lado, também podemos visualizar os mais diversos movimentos fundamentalistas que eclodem no seio das sociedades contemporâneas. Privilegiando a perspectiva pluralista das religiões - em detrimento da visão exclusivista e inclusivista - Pui-Lan afirma que "Se a religião quiser tornar-se uma força de construção da paz e não causa de intolerância e conflito, novas construções e novas relações com o 'outro diferente quanto à religião’ devem ser buscadas” (PUI-LAN, 2015, p. 32).

Entrementes, sem desconsiderar a história do movimento ecumênico que, de acordo com seu texto, guarda uma série de contradições no que se refere às vozes subalternas - principalmente as femininas! -, a autora considera que o diálogo interfé tem muito a ganhar com as críticas elaboradas pelas pensadoras e pensadores pós-coloniais, sobretudo no que tange às reflexões em torno do tema da alteridade. Para Pui-Lan "O diálogo interfé se beneficiaria das intuições de estudos pós-coloniais, que questionam como o eu e o outro, o centro e a periferia, o dominador cultural e o marginalizado foram construídos" (PUI-LAN, 2015, p. 32-33).

Não obstante, com os olhos voltados para dentro do próprio movimento ecumênico, por meio de uma autocrítica, por assim dizer, Pui-Lan passará para o segundo capítulo de seu texto. Neste, seu foco recobrirá as questões de gênero, que, aliás, dá título ao seu livro. E justamente por conta do silenciamento dessas questões, é indispensável ouvirmos as vozes femininas. Isso pois, conforme afirma Pui-Lan, "Desafortunadamente, em muitos encontros ecumênicos e no Parlamento Mundial de Religiões, a participação das mulheres e suas vozes foram marginalizadas" (PUI-LAN, 2015, p. 33).

Assim, uma vez que historicamente o diálogo interfé tem sido marcado pela preponderante presença masculina, a autora propõe que "O desafio do gênero é o desafio da alteridade, no qual a mulher, no diálogo, pode ser duplamente outra, se ela for mulher de outra crença em uma reunião constituída predominantemente por homens" (PUI-LAN, 2015, p. 35). A esta altura, seria importante destacarmos a coerência e honestidade intelectual de Pui-Lan no que se refere ao imperativo de ouvirmos as vozes femininas. Eis a 
lista de autoras trazidas à baila do seu debate, algumas delas são: Diana Eck, Catherine Cornille, Judith A. Berling, Ursula King, Dulcie Abraham, Prasetya Murniati, Marlene Perera, Rita M. Gross, Jasmin Zine, Gayatri Chakravorty Spivak, Leila Ahmed, Yvone Yazbeck Haddad, Amina Wadud-Muhsin, Laleh Bakhtiar, Jane Idleman Smith, Judith Paskow, Toinette M. Eugene, Ada María Isasi-Díaz, Mary Hunt, Ellen M. Umansky, Andréa Smith, Jeannine Hill Fletcher, Nancy Chodorow, Carol Gillican, Catherine Keller, Ivone Gebara.

De qualquer forma, atenta às insuficiências dos esforços da "boa vontade", ou seja, ciente de que não basta "dar a voz" à outra(o) para que o diálogo se estabeleça de forma equitativa, Pui-Lan nos chama a atenção para três conceitos fundamentais - a nosso ver, aqui se concentra a maior contribuição teórica da autora neste texto. A saber, o primeiro conceito diz respeito à noção de diferença de poder. Tal noção pode ser introduzida a partir da seguinte questão: "porque mulheres de credos diferentes não entram no diálogo em pé de igualdade” (PUI-LAN, 2015, p. 38). Para a autora, não basta nos colocarmos todos em posição de diálogo - a exemplo de mulheres cristãs e muçulmanas em torno de uma mesa. Isso pois, se não se leva em conta o lugar de onde fala cada uma e as diferenças de poder a que estão circunscritas, o que invariavelmente irá ocorrer é que ao invés de privilegiar a alteridade, se reforcem as subalternidades e a dominação.

Para não incorrer nesse tipo de erro, Pui-Lan afirma que desde o início é importante que sejam estabelecidas as linhas que orientarão o diálogo, a fim de que haja uma descentralização do poder. De tal modo, que o outro ou a outra, não seja "constantemente forçada a comparar-se com a norma da maioria ou com a norma dominante" (PUI-LAN, 2015, p. 50). Além disso, como a autora assevera "no diálogo interfé, os participantes que pertencem à tradição dominante precisam instruir-se sobre as outras tradições religiosas a fim de conceder a todos as mesmas condições" (PUI-LAN, 2015, p. 51).

A sua segunda contribuição crítica se refere à noção de apropriação. A esse respeito, Pui-Lan diz que "A mera inclusão de algumas vozes simbólicas, sem reconsiderar fundamentalmente as pressuposições e os esquemas epistemológicos atuantes não é verdadeira diversidade" (PUI-LAN, 2015, p. 52-53). E aqui poderíamos citar as apropriações indevidas realizadas pelas várias expressões da Nova Era para com as tradições nativas. Malgrado, por meio da apropriação "Os rituais indígenas são tirados do contexto e empacotados novamente para consumo e lucro dos brancos, sem respeitar a integridade deles e seu uso nas comunidades indígenas" (PUI-LAN, 2015, p. 57). 
Para exemplificar a operação de apropriação indevida, citamos os emblemáticos casos ocorrentes nas reuniões inter-religiosas. Na ausência de representantes índios, realizam-se momentos litúrgicos com músicas e apresentações típicas, como uma espécie de lampejos da cultura indígena. Ou seja, apropriam-se da cultura do índio mesmo que não demonstrem qualquer comprometimento e responsabilidade pelos povos nativos. De acordo com Pui-Lan, isso ocorre por três razões básicas, que para ela se constituem como armadilhas: a) A negação: que se estabelece a partir da ideia de que os índios estejam em extinção, e que por isso se faz necessário "proteger" os elementos culturais do passado, para que sejam preservados na memória; b) A sindrome de querer ser indio: comum em culturas brancas que fetichizam as culturas nativas e o nativo por meio de imaginações românticas e utópicas - a exemplo do bom selvagem; e c) A culpa em busca de redenção - que leva pessoas brancas, cientes dos estragos realizados à cultura indígena, a se interessarem pelas culturas nativas a fim de que tenham os seus débitos emocionais sanados.

Já no que diz respeito à sua terceira contribuição teórica, temos o bibridismo. A partir das contribuições de Jeannine Hill Fletcher, Pui-Lan para além da noção identitária masculinista do eu-como-autônomo, irá recomendar a teoria do eu-em-relação. Pautada na ideia de que todos somos híbridos, e que não há identidade pura ou isenta de intercambiamentos simbólicos, irá propor três razões pelas quais o hibridismo pode favorecer o diálogo interfé. i) A identidade híbrida pode estimular conexões com membros de fora do nosso grupo; ii) A identidade híbrida leva em conta a identificação parcial de identidades sobrepostas, o que possibilita acontecer a colaboração para além das fronteiras religiosas; iii) A identidade híbrida desafia a pureza que leva em conta a dupla ou múltipla pertença religiosa (PUI-LAN, 2015, p. 62-63).

Ainda em relação à noção de bibridismo, a autora sinalizando certo limite nas conclusões de Fletcher, recorre ao pensador pós-colonial Homi Bhabha, especificamente no que diz respeito à sua noção de ambivalência. Isso para evitar de incorrer em relativismos multiculturalistas que porventura possam instrumentalizar o pluralismo religioso, assimilando-o à dinâmica perversa do capitalismo globalizado. Conforme vaticinam as palavras de Pui-Lan: "Quando se suprimem o contexto colonial e o corte político do hibridismo, é possível ser facilmente cooptado para glorificar o pluralismo e a multiplicidade em nosso mundo globalizado, como livre movimento de comércio e de capital” (PUI-LAN, 2015, p. 67).

Enfim, após apresentar o potencial dos esforços interfé na construção de uma cultura de paz, não obstante indicar as armadilhas que podem com- 
prometer tal objetivo, Pui-Lan irá se voltar em seu terceiro capítulo para o diálogo em si; irá encerrar seu livro com a noção de polidoxia. Com ele, por meio do desmascaramento da tirania do único, a autora pretende ultrapassar a ortodoxia, crença essa que oblitera a possibilidade de o diálogo autêntico se efetivar. Para a autora, o termo polidoxia capta "a ideia de que os cristãos não tem monopólio da revelação de Deus, e que a divindade deveria ser compreendida em termos de multiplicidade, irrestringibilidade e relacionalidade" (PUI-LAN, 2015, p. 74). Dessa maneira, a contrapelo do estatuto monoteísta e sua lógica do único imutável, reivindicando a multiplicidade, a pluralidade e a fluidez da linguagem humana e suas falas acerca do sagrado, Pui-Lan diz que "A polidoxia insiste que nenhuma teologia ou credo pode exaurir o sentido de Deus e alegar infalibilidade doutrinal. [...] A polidoxia partilha a afinidade com a teologia apofática, que insiste que a natureza de Deus não pode ser plenamente descrita, e que só podemos falar a respeito do que Deus não é, em vez de sobre o que Deus é" (PUI-LAN, 2015, p. 75-76). Finalmente, por meio da polidoxia Pui-Lan expõe os limites da razão ocidental, e nos apresenta a magnitude de seu empreendimento, que a nosso ver é sobretudo ético. Rompendo com as pretensões totalitárias ocidentais que através do pensamento ontológico moderno pensa esgotar o outro no si, a alteridade na identidade, o feminino no masculino por assim dizer, ela deseja abrir caminho para a alteridade do outro; sobretudo a partir do protagonismo feminino - as "duplamente outras" conforme afirma Pui-Lan. Para tanto, a autora busca superar as concepções tradicionais acerca das identidades religiosas, que a partir de prerrogativas masculinistas-exclusivistas inibem o acesso ao reconhecimento de um(a) outro(a) que seja diferente do mesmo. Enfim, ao demonstrar que a alteridade é constitutiva do ser que na verdade sempre é inter-ser - ou seja, que o eu só é eu por conta de sua interação com o outro -, Pui-Lan nos mostra que o diálogo interfé pode e muito contribuir para a construção de uma cultura da solidariedade e da paz que não seja violenta.

\section{Referência}

PUI-LAN, Kwok. Globalização, gênero e construção da paz. São Paulo: Paulus, 2015, $95 \mathrm{p}$.

Submetida em: 20-10-2016

Aceita em: 9-8-2017 